\title{
I've Got My Virtual Eye On You: Remote Proctors And Academic Integrity
}

Louis F. Tomasi, Troy University, USA

Victoria L. Figiel, Troy University, USA

Murray Widener, Troy University, USA

\begin{abstract}
This paper discusses the challenges of online teaching, the reasons students cheat and one means of curtailing that cheating in the online environment. The use of Securexam Remote Proctor System in one university application is reviewed.
\end{abstract}

Keywords: Online teaching, proctor

\section{INTRODUCTION}

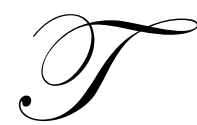

eaching online brings challenges in many respects including ensuring the academic integrity of the course. Some students may be half-a-world away from the instructor when completing an assignment. When a student is on a computer a thousand miles away, how is an instructor to ensure that the student is working in a way that protects the legitimacy of the course (Rowe, 2004)?

Carlson, Davis and Wyatt (2003) discussed emerging problems with administering tests and written assignments online. Dunning and Shetterly (2004) detailed the ethics and bad collection that is attributed to integrity in virtual campus classes. The problem has only grown with the tremendous increase in virtual campus learning, i.e., eCampus, and remote teaching in recent years. Test taking and academic integrity in traditional settings are still an issue now transported to a new environment. Argyle (2003) devoted an entire paper to the issue of written assignments in distance learning (DL) environments and maintaining academic integrity.

This paper looks at the implementation of a remote proctoring system as a means to thwart opportunities for cheating in the virtual classroom setting.

\section{CHEATING IN GENERAL}

Traditional students incorporate many creative methods of cheating on assignments including sneaking crib notes, writing on match books and matches, printing hard on paper to ensure the impression of answers are invisibly printed on succeeding pages, writing the answers on the bills of baseball caps, and building files for student access that contain copies of previous tests among countless others. Recently, with the ubiquitous use of text messaging, students can even send answers to each other while taking a test. On-line students have, likewise, found creative means of cheating in their environment as well. If not proctored, students can have friends help them with assignments, or even use the text and Internet to find answers.

Between 40 and 70 percent of all college students have reported cheating at sometime during their academic careers (Davis, 1992). Aiken (1991) identified factors that influence academic dishonesty. Some of the motives for dishonesty in an educational setting include the following: the rivalry among students to achieve higher grades; parental demands to produce high grades; student perceptions that institutional demands may be unreasonable; disproportionate and too demanding students who believe that university professors are callous and unsympathetic to the students' needs; slipshod implementation of corrective measures on the part of college professors; peer pressure to make tests and answers available to others; and an attitude of competition between professors and students; i.e., "got-you” (Barnett \& Dalton, 1981). 


\section{HONOR CODES AND ETHICS}

There are approximately 4,000 post secondary educational institutions in the United States. Less than 300 implement codes of honor addressing ethical concerns in completing university-level assignments (Dodd, 2007).

The U.S. Military Academy incorporates one simple phrase for its assignments, "I will not lie, cheat or steal nor tolerate those who do." (Jones, n.d.) While incidents of cheating at the military academies may be arguably quite low, it still exists. One recent example had fifteen students removed from the Air Force Academy for cheating (Fifteen booted, 2007).

According to the Clemson University Center for Academic Integrity (Dodd, 2007), the level of plagiarism and written academic dishonesty drops to $25-33 \%$ at universities that implement an academic honor code. Clemson Center points to a number of academic investigations that conclude that the occurrence of academic dishonesty is approximately $30-50 \%$ lower than on campuses without an academic honor policy.

\section{CORRECTING THE PROBLEM}

The problem of cheating in the university setting beckons the simple question, "Now what?"

According to Timothy M. Dodd (2007), Executive Director of the Center for Academic Integrity, an honor code is a must and the elements of an ideal honor code would include the following:

1. Speaks to consensus institutional values.

2. Enforceable and culturally appropriate proscriptions, prescriptions and practices.

3. Student involvement and ownership.

4. Students are primary educators (and are recruited from among acknowledged student leaders and esteemed peers).

5. $\quad$ Streamlined process (to reduce the "hassle factor" for faculty and students).

6. Competent and reliable investigation (often conducted by a trained, impartial and permanent judicial investigator).

7. Fair and consistent adjudication and sanctioning.

8. Central recordkeeping that merges academic and non-academic infractions into a single disciplinary file environment.

Notice however, that in the ideal elements mentioned, there is little provisions for the virtual/on-line

\section{Cyber-Plagiarism}

Within the past decade, the number of universities offering virtual courses and/or hybrid classes has increased greatly. With this increase, there are now several incidences of cyber plagiarism (Bulkeley, 1992). In a research study conducted by Quan (2001), over two-thirds of a sample of 2100 students polled self-admitted that they committed at least one academically dishonest offense such as plagiarism when submitting university level assignments.

Cyber-plagiarism is defined as the "copying and downloading in part, or in their entirely, articles or research papers located on the Internet or coping ideas found on the Web and not giving proper attribution" (Terminology, n.d.). The University of Alberta provides guidelines to stem cheating on its web site and addressing corrections that may be made in the following areas: clarification of what constitutes cheating, use of the syllabus to support academic integrity, discussions on integrity, and assignment design (Preventing Plagiarism, n.d.). Still, discussion on integrity are difficult, but not impossible, to manage in the on-line setting. 


\section{On-Line Instruction And Cheating}

Initial methods to maintain integrity in on-line instruction included the use of human proctors (Davis, Grover, Becker, \& McGregor, 1992), changing exam questions as often as practical, creating individualized tests for students, on-line testing to include written essays, use of plagiarizing software, scrambling of existing test questions (Singhal \& Johnson, 1983,) and the use of test question pools and passwords. Test pools may contain 100 to 150 questions or more. For example, some Sport Management on-line instructional textbooks may have as many as 3003500 suggested test questions.

Software programs such as Turnitin, and others, have given instructors powerful and thorough search engines for the detection of plagiarism in written assignments (Foster, 2002). Implementing testing time limits on on-line assignments is another deterrent to cheating. Some professors use a guideline of one to two minutes per test question when the question is multiple-choice.

While passwords, timed exams, test format, and other technique make cheating a challenging task for the student, these methods do not ensure the student's exclusive individuality. As mentioned, one resolution to exclusive verification was to use a human being proctor. The human proctor need not be the instructor, removing assessment management a role for the professor, but it also eliminated the real meaning of distant schooling, i.e., the enrollment into university courses "anytime and anywhere".

\section{Remote Proctor}

One application that promotes academic integrity, but eliminates the obligation for students' proctored exam is the use of a remote proctor. Securexam Remote Proctor System is one solution for universities, colleges, and other institutions of higher learning that aspirate to preserve their accreditation and academic integrity of the examination experience offered in on-line situations. This virtual proctor is a collaborative effort between Troy University-eCampus, and Securexam Remote Proctor (Software Secure, n.d.).

The result is a system that eliminates the necessity for students to travel to locations to have a human proctored secure examination. The eCampus distant proctor arrangement uses secure software, biometrics, audio, and video verification to ensure the identity of a test-taker. The Securexam Remote Proctor System reassures academic integrity using a series of eCampus protected procedures such as: fingerprints, voice, video, and interference with calculator memory (Putka, 1992), and the use of computer-desktop locking software.

The eCampus student may complete every exam in an on-line exam environment. For nontraditional students, they do not need to travel an educational testing site to locate a proctor. For instructors and the university, they are assured that their remote testing has integrity as well as is suitable for the student population. The use of remote proctoring is imperative in that it eliminates a roadblock to practical, extensive distance education.

\section{Use Of Remote Proctor}

These remote proctor scanners authenticate all virtual learners and compare their entered-finger print with the fingerprint the students provided when the students enrolled for the Remote Proctor System. Remote proctor verifies the virtual learner's voice. The camera assembled onto the pedestal atop the student's computer records a panoramic 360-degree synchronized video and audio recording of the surroundings throughout the time the assessment is underway. Suspicious noises, movement and action are recorded during the assessment session. This recording and virtual proctoring eliminate the necessity for steady monitoring. With motion and sound sensitivity, this system economizes professors' proctoring time and facilitates professors honing in directly to questionable academic practices during the assessment.

This Troy University eCampus remote proctor application decreases the need for student and university expense associated with travel to an approved testing center to complete the assessment. Without a cost effective method to ensure academic integrity, the growth of distance instruction could be hampered. 
Additionally, the use of computer-locking software, used in combination with Software Secure's suite of Securexam software, almost guarantees that the student has access to the assessment only. No web-surfing, email, instantaneous messaging, Microsoft Office or other software is reachable when using the virtual Remote Proctor.

\section{Consequences And Future Avenues For Research}

There is obviously a cost for implementation of a system like a remote proctor, so the benefits must be weighed against the specific implementation. Often this can be a rather nebulous benefit amount measured against specific real dollar figures to purchase the system. Still, the benefit must also incorporate the perception of increased academic rigor and verifiability that uses of tools like remote proctoring bring to accrediting discussions for the programs that use it (SACS, 2007a; SACS, 2007b).

Several avenues for future research exist. Comparison to other software and hardware methods of remote proctoring should allow discussion of a "best-in-class" product. Also, research on whether actual integrity issues are reduced with remote proctoring would also help in the costing discussions mentioned previously. Perhaps portions of a full implementation could be assessed to see if less than the implementation mentioned here provides the same benefits.

\section{CONCLUSION}

Teaching online is a challenging exercise for the student and instructor. Ensuring the academic integrity of the course is of paramount importance to the students, instructors, and the university. This paper reviewed one implementation of a remote proctoring system as a means to frustrate opportunities for cheating in the online. The implementation described here is working to add an additional measure of integrity to the academic environment at Troy University eCampus. Still, there is room for more study and research in this relatively new area.

According to one professor at TROY; "Having the Securexam Remote Proctor System in class permits me to safeguard the academic integrity of distance education at the same time upholding university standards. The Securexam Remote Proctor System facilitates the maintenance of exam honesty and the 'anytime, anywhere' flexibility of online education." - Dr. Murray Widener, professor of Public Administration at Troy University.

\section{REFERENCES}

1. Aiken, L. R. (1991). Detecting, understanding and controlling for cheating on tests. Research in Higher Education, 32(6), 725-736.

2. Barnett, D. C., \& Dalton, J. C. (1981). Why college students cheat. Journal of College Student Personnel, 22(6), 545-551.

3. Bulkeley, W. M. (1992, April, 28) High tech aids make cheating in school easier. Wall Street Journal, B1, B6.

4. Carlson, P., Davis, S., \& Wyatt, H. (2003). Evaluating on-line education: Comparison of on-line, traditional and merged-format coursework. Paper presented at the meeting of the Teaching Public Administration Conference. Dayton, OH.

5. Davis, S. F., Grover, C. A., Becker, A. H., \& McGregor, L. N. (1992). Academic dishonesty: Prevalence, determinants, techniques, and punishments. Teaching of Psychology, 19(1), 16-20.

6. Dodd, T. M. (2007). Honor code 101: An introduction to the elements of traditional honor codes, modified honor codes and academic integrity policies. Retrieved May 22, 2008, from http://www.academicintregity.org/educational_resources/honor_code 101.php

7. Dunning, P. \& Shetterly, D. (2004) Teaching MPA students using a distance education format: Techniques to promote academic integrity. Paper presented at the meeting of the Teaching Public Administration Conference. Madison, WI.

8. Fifteen booted from Air Force Academy for cheating. (2007, May 01). USA Today. Retrieved May 22, 2008 from http://usatoday.com/news/education/2007-05-01-academy-cheating_n.htm

9. Foster, A. (2002, May, 17) Plagiarism-detection tool creates legal quandary. The Chronicle of Higher Education, http://chronicle.com/free/v48/136/36a03701.htm 
10. Jones, D. (n.d.). United States Military Academy's honor code and system. Retrieved May 23, 2008, from http://www.usma.edu/cpme/HS_Outreach/WestPoint's\%20Honor\%20Code\%20and\%20System.pdf

11. Preventing plagiarism. (n.d.). Retrieved May 22, 2008, from http://www.library.ualberta.ca/guides/plagiarism/preventing/index.cfm

12. Putka, G. (1992, June, 29) A cheating epidemic at a top high school teaches sad lessons. Wall Street Journal, Al, A4-A5.

13. Quan, D. (2001, Feb, 16) Universities combat rising Internet plagiarism. The Ottawa Citizen, F1.

14. Rowe, N. (2004) Cheating in online student assessment: Beyond plagiarism. Retrieved on March 18, 2007 from, http://www.westga.edu/ distance/ojdla/summer72/rowe72.html

15. SACS. (2007a) Best practices for electronically offered degree and certificate programs. Retrieved on March 11, 2007 from http://www.sacscoc.org/pdf/commadap.pdf

16. SACS. (2007b) Distance education policy statement. Retrieved on March 11, 2007 from http://www.sacscoc.org/pdf/081705/distance\%20education.pdf

17. Singhal, A., \& Johnson, P. (1983) How to halt student dishonesty. College Student Journal, 17(1), 13-19.

18. Software Secure, Inc, (2007) Securexam remote proctor administrator's guide. Software Secure Inc., Boston, Mass.

19. Terminology. (n.d.). Retrieved May 22, 2008, from http://www.library.ualberta.ca/guides/plagiarism/terminology/index.cfm\#cyberplagiarism

\section{NOTES}




\section{NOTES}

